\title{
Possible Role of Bone $\gamma$-Carboxyglutamic Acid-Containing Protein in the Pathogenesis of Vitamin K Deficiency in Early Infancy
}

\author{
Muneyoshi Yoshinaga,,${ }^{1} *$ Yoshiro Tsuji, ${ }^{1}$ Chiharu Tsutsumi, ${ }^{2}$ \\ and Sachiko MORIUCHI ${ }^{2}$ \\ ${ }^{1}$ Department of Pediatrics, Nagasaki University, School of Medicine, \\ Nagasaki 852, Japan \\ ${ }^{2}$ Department of Food and Nutrition, School of Home Economics, \\ Japan Women's University, Mejirodai, Tokyo 112, Japan
}

(Received October 6, 1986)

Summary In order to investigate the pathogenesis of vitamin K deficiency in early infancy, we measured urinary $\gamma$-carboxyglutamic acid (Gla) by high performance liquid chromatography, plasma and urinary bone Gla-containing protein (BGP) by radioimmunoassay, and vitamin K-dependent coagulation activity by Normotest, in newborn and 1-3month-old infants. The infants were divided into two groups, one of which received vitamin $\mathrm{K}$ orally at birth and at the 7 th day thereafter, and the other, which did not receive vitamin $\mathrm{K}$, was taken as the control. Urinary Gla level in the control group was fairly steady during early infancy, whereas in the vitamin K-administered group urinary Gla increased with age and was significantly higher than that of the control group from the neonatal period to 1 month of age. The difference in urinary Gla level between the two groups was maximum at 1 month of age. Coagulation activity in both groups increased with age and the activity in the vitamin $\mathrm{K}$-administered group was slightly higher than that in the control, however, the slopes for age versus coagulation activity between the two groups were not significantly different. Plasma BGP level in the control group increased linearly during the neonatal period and then significantly decreased at 1 month of age. The urinary BGP level in the control group increased linearly from the neonatal period to 3 months of age. On the other hand, the plasma BGP level in the vitamin $\mathrm{K}$-administered group was significantly lower compared with that in the control group from 2 days of age to 1 month, and the urinary BGP level was also lower than in the control during the neonatal period but higher

*To whom correspondence should be addressed. 
than in the control at 1 month of age. Urinary Gla mostly increased at 1 month of age when vitamin $\mathrm{K}$ was administered, indicating that there are newly synthesized non- $\gamma$-carboxylated, vitamin $\mathrm{K}$-dependent proteins which are changed to the $\gamma$-carboxylated form and excreted in urine as free Gla by vitamin $\mathrm{K}$ administration, especially at 1 month. The decreased BGP level at 1 month of age in the control group suggests that BGP in plasma deposits to bone, because there is no significant change detected in urinary BGP and Gla. Moreover, the high urinary BGP level at 1 month of age in the vitamin $\mathrm{K}$-administered group suggests that excessive BGP, which is formed as the result of increased bone turnover at 1 month, is the source of this high urinary level. Therefore it is speculated that increased BGP turnover to regulate mineralization at 1 month of age, and induce acceleration of vitamin $\mathrm{K}$ requirement of the body and consequently infants easily manifest vitamin $\mathrm{K}$ deficiency if there are risk factors decreasing vitamin $\mathrm{K}$ intake.

Key Words: vitamin $\mathrm{K}$ deficiency, $\gamma$-carboxyglutamic acid (Gla), bone Gla containing protein, infant

Vitamin $\mathrm{K}$ deficiency of the newborn has been well recognized for a long time. Recently it has become apparent that vitamin $\mathrm{K}$ deficiency is also a major cause of acute intracranial hemorrhage in infants older than 1 month [1-10]. This late hemorrhagic disease can be idiopathic or may occur as a secondary manifestation of an underlying disorder. Secondary cases are caused by decreased intestinal absorption of vitamin $\mathrm{K}$, such as occurs with chronic diarrhea and biliary atresia, by decreased vitamin $\mathrm{K}$ synthesis by intestinal flora secondary to the administration of antibiotics, and by the disturbance of vitamin $\mathrm{K}$ utilization in the liver. Idiopathic cases, whose underlying cause has not been identified, usually occur between 1 and 3 months of age, the peak incidence being at 1 month. The pathogenesis of idiopathic late hemorrhagic disease is not clearly understood, however, it is speculated that breast feeding is the most important contributing factor for vitamin $\mathrm{K}$ deficiency, because most of the infants manifesting bleeding diathesis have been breast-fed $[4-7,9,10]$. It is reported that the vitamin $\mathrm{K}$ content of the brest milk fed to these infants is very low compared with that in controls or in formula [10-12]. Moreover, it is well known that the intestinal flora of breast-fed infants may produce less vitamin $\mathrm{K}$ than the flora of formula-fed infants [13]. But it is difficult to explain the high incidence of late hemorrhagic disease at 1 month of age only by poor vitamin $\mathrm{K}$ intake, especially in idiopathic cases.

On the other hand, vitamin K-dependent, calcium-binding protein, which contains $\gamma$-carboxyglutamic acid (Gla), has been found in bone [14-16]; and vitamin $\mathrm{K}$ is also thought to have an important role in bone metabolism, as well as blood coagulation factors [17]. This protein, known as bone Gla containing protein 
(BGP) or osteocalcin, is one of the most abundant non-collagenous bone proteins in EDTA extracts of bone [18]. The function of BGP is not clearly understood, however, it is thought to be involved in bone calcification or in regulation of calcium between bone and blood. Because the growth and development of bone are greatest during early infancy, the role of BGP related to vitamin $\mathrm{K}$ metabolism as well as blood coagulation factors in this period should not be overlooked.

For an understanding of the high incidence of late hemorrhage disease at one month of age, therefore, age-related physiological changes in plasma and urinary BGP levels, and urinary Gla excretion were determined and compared in detail with those of blood coagulation activity. Moreover, the effects of vitamin $\mathrm{K}$ administration on these changes were observed in comparison with a case of vitamin $\mathrm{K}$ deficiency with intracranial hemorrhage.

\section{MATERIALS AND METHODS}

\section{Chemicals}

All chemicals used were of analytical grade (Wako Fine Chemical Co., Osaka). ${ }^{125}$ I was purchased from New England Nuclear (U.S.A.). Anti-rabbit Ig-G goat serum was purchased from Miles-Yeda Ltd. (Israel). Gla-monoammonium salt and hydroxyapatite were purchased from Calbiochem-Behring Co. (La Jolla, Calif.). Nucleosil 5SB was purchased from Neigel Co. (FRG). Normotest reagent was purchased from Nyegaard \& Co. A/S (Oslo, Norway). Kaytwo syrup was supplied by Eisai Co., Ltd. (Tokyo).

\section{Subjects and experimental design}

The total number of infants whose urinary Gla level was measured was 1,092, and consisted of 634 of newborns, 379 of 1-month-old infants, and 79 of 3-monthold ones. Coagulation activity of 525 and plasma and urinary BGP of 232 of these subjects were also determined. All of them were normal term infants, and premature or low-birth-weight infants as well as the infants who had underlying causes of vitamin $\mathrm{K}$ deficiency such as biliary atresia, prolonged diarrhea, and antibiotic therapy were excluded from this study. The infants were randomly divided into two groups: one group received vitamin $\mathrm{K}$ (vitamin $\mathrm{K}$-administered group), and the other group did not (control group). In the vitamin $\mathrm{K}$-administered group, $1 \mathrm{ml}$ of Kaytwo syrup ( $2 \mathrm{mg}$ of menaquinone- $4 / \mathrm{ml}$ syrup) was given on the day of birth and $2 \mathrm{ml}$ on the $7 \mathrm{th}$ day. Adding to these comparative studies, we examined the effects of vitamin $\mathrm{K}$ administration on the levels of plasma BGP and urinary Gla in a case of coagulopathy involving vitamin $\mathrm{K}$ deficiency with intracranial hemorrhage.

\section{Measurement of urinary Gla}

High-performance liquid chromatography (HPLC) of urinary Gla was performed by the method of Kuwada and Katayama [19]. Chromatographic separation 
was carried out on a $4.6 \mathrm{~mm} \times 25 \mathrm{~cm}$ column with Nucleosil $5 \mathrm{SB}$ anion exchanger, which was maintained at $48^{\circ} \mathrm{C}$ in a column oven. The elution buffer was $0.05 \mathrm{M}$ sodium citrate, $\mathrm{pH} 4.25$. The flow rate of the buffer was maintained at $0.5 \mathrm{ml} / \mathrm{min}$ with a Shimadzu LC-3A pump. The eluate from the column was mixed with $o$ phthalaldehyde (OPA) reagent, which was dispersed with a Shimadzu PRR-2A pump at a flow rate of $0.3 \mathrm{ml} / \mathrm{min}$. The OPA reagent was prepared according to the method of Benson and Hare [20]. Fluorescence was detected by excitation at $240 \mathrm{~nm}$ and emission at $445 \mathrm{~nm}$ using a Shimadzu fluorescence spectrometer RF530 , and peak areas were calculated by a Shimadzu C-R1A data processor. The urine was filtered with a $0.45 \mu \mathrm{m}$ membrane filter, diluted with an equal volume of water, and then injected (10-20 $\mu$ ) with a Waters Intelligent Sample Processor Model 710B automatic sample injector. All data on urine were related to creatinine excretion.

\section{Measurement of vitamin $K$-dependent coagulation activity by Normotest}

Normotest [21] was carried out in the following manner: capillary blood of $10 \mu \mathrm{l}$ obtained by plantar puncture was immediately mixed with $0.25 \mathrm{ml}$ of the warmed Normotest reagent $\left(37^{\circ} \mathrm{C}\right)$ and the clotting time was measured. The coagulation activity as a per cent of normal (Normotest value) was obtained from the calibration curve.

\section{Radioimmunoassay for plasma and urinary $B G P$}

Radioimmunoassay was performed by the method of Price and Nishimoto [22]. Human BGP has cross-reactivity with bovine BGP [22], therefore, we purified bovine BGP according to the method of Otawara et al. [23] and prepared antibovine BGP sera. Assay solution (0.14 M NaCl, $10 \mathrm{~mm}$ phosphate, $10 \mathrm{~mm}$ EDTA, $0.1 \%$ Tween 20 at $\mathrm{pH} 7.4$ ) contained a known amount of unlabeled BGP, 50-100 $\mu l$ of human plasma or urine in $200 \mu 1$ of assay solution, and $100 \mu 1$ of anti-bovine BGP rabbit serum (a final dilution of $1: 800$ ) in $200 \mu$ l of assay solution. After incubation for $24 \mathrm{~h}$ at $4^{\circ} \mathrm{C}$, about $10,000 \mathrm{cpm}$ of $\left[{ }^{125} \mathrm{I}\right]$-labeled bovine BGP in 100 $\mu \mathrm{l}$ of assay solution was added. After $24 \mathrm{~h}$ at $4^{\circ} \mathrm{C}$, the assay was terminated by precipitation of rabbit antibody on the addition of 5-20 $\mu \mathrm{l}$ of goat antiserum to rabbit $\gamma$-globulin. Then the reaction mixture was centrifuged at $3,000 \times g$ for $5 \mathrm{~min}$ to sediment $\left[{ }^{125} \mathrm{I}\right]$-labeled BGP bound to rabbit antibody and the supernatant was discarded. Background [125I]-labeled BGP which nonspecifically adhered to the precipitate or to the assay tube was measured by incubation of $\left.{ }^{125} \mathrm{I}\right]$-labeled BGP with normal rabbit serum without specific antiserum followed by the usual second antibody precipitation. Total and antibody-bound [ $\left.{ }^{125} \mathrm{I}\right]$-labeled BGP were determined by a gamma counter (Aloca ARC-221). The fraction of $\left.{ }^{125}{ }^{12}\right]$-labeled BGP bound to antiserum is defined as $\mathrm{cpm}$ in precipitate minus $\mathrm{cpm}$ in background divided by total cpm in assay (B/Bo). 


\section{Hydroxyapatite binding assay of plasma $B G P$}

Hydroxyapatite binding assay of plasma BGP was carried out to determine the relative amounts of $\gamma$-carboxylated and non- $\gamma$-carboxylated BGP in plasma by the method of Price et al. [24]. In this assay, $50 \mu 1$ of plasma whose total BGP content had been determined was added to a tube containing $20 \mathrm{mg}$ of hydroxyapatite. The mixture was then vortexed, turned end-over-end at $4^{\circ} \mathrm{C}$ for $30 \mathrm{~min}$, and centrifuged for $10 \mathrm{~min}$ in a table-top clinical centrifuge. The supernatant, which contained BGP unable to bind to hydroxyapatite, was removed and saved for radioimmunoassay.

\section{Statistics}

The group means were compared by Student's-t-test with the assumption of the equality of variance, or by the Welch-t-test without the assumption, after estimation of equality of variances by Leven's test.

\section{RESULTS}

Effect of vitamin $K$ on changes in urinary Gla level, Normotest value, plasma and urinary BGP levels during normal growth and development in early infancy

The effects of aging and vitamin $\mathrm{K}$ administration on the urinary Gla level in 0-3-month-old infants are shown in Fig. 1. In the control group, the urinary

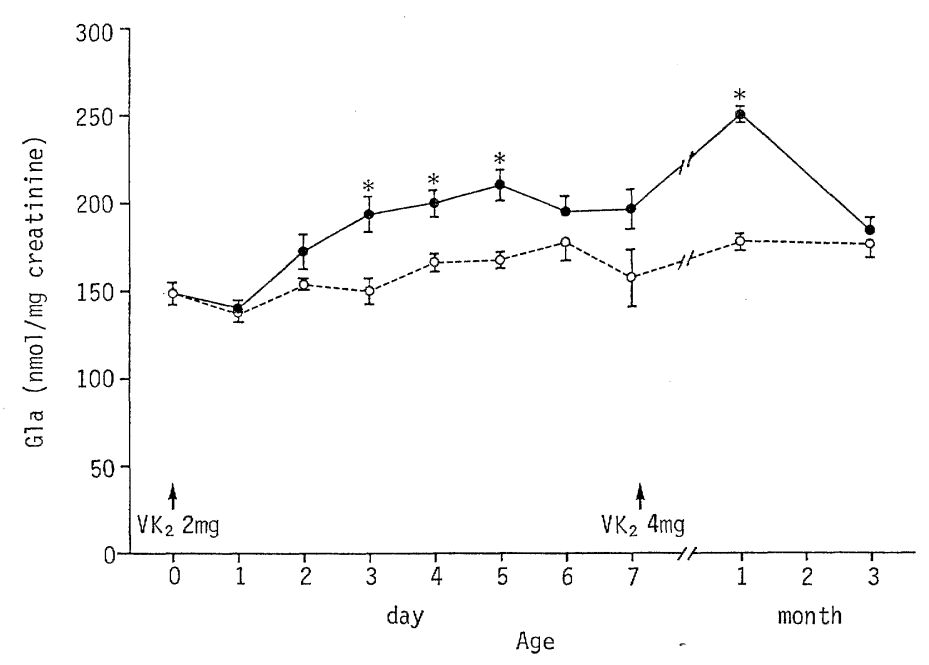

Fig. 1. Effects of aging and vitamin $\mathrm{K}$ administration on urinary Gla level in 0-3-month-old infants. Each point represents the mean \pm SE. Number of infants was; 17 of 0 day old, 32-42 of newborn, 144 of 1-month-old, 42 of 3-month-old in the control group (--- ---), 40-70 of newborn, 235 of 1-month-old, 37 of 3-month-old in the vitamin K-administered group (- -). *Significantly different from the control group each day at $p<0.01$. 
Gla level slightly increased with age, however, the increase was not so significant. On the other hand, the increment of the urinary Gla level in the vitamin K-administered group was significantly high compared with that in the control group on

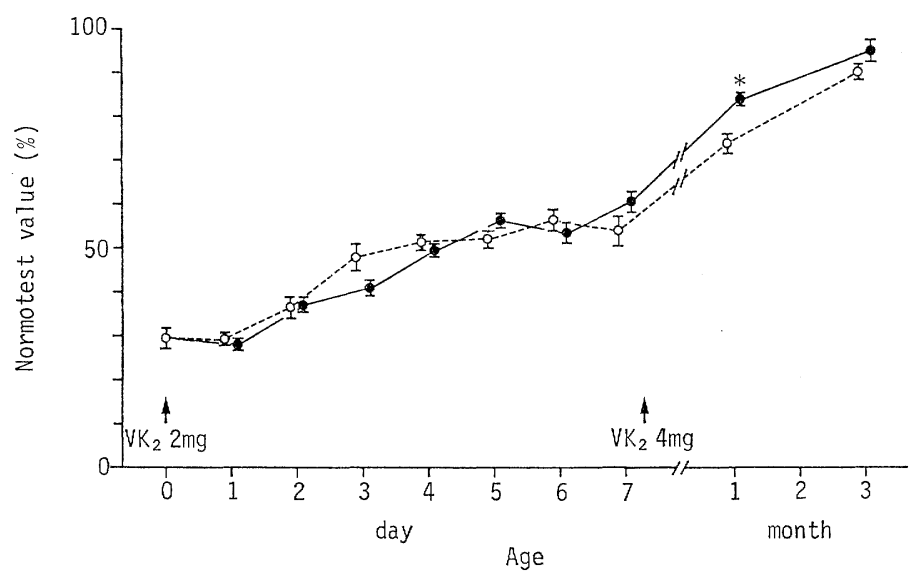

Fig. 2. Effects of aging and vitamin $\mathrm{K}$ administration on Normotest value in 0 -3-month-old infants. Each point represents the mean \pm SE. Number of infants was; 12 of 0 day old, 15-24 of newborn, 65 of 1-month-old, 24 of 3-month-old in the control group (--- ----), 22-33 of newborn, 111 of 1-month-old, 34 of 3-month-old in the vitamin K-administered group (- -). *Significantly different from 1-month-old control group at $p<0.01$.

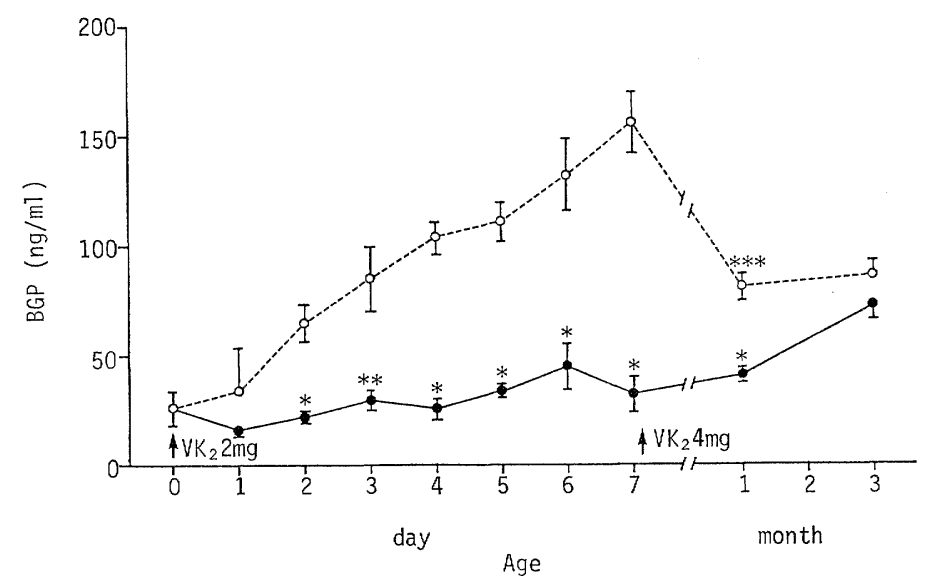

Fig. 3. Effects of aging and vitamin $\mathrm{K}$ administration on plasma BGP level in 0-3-month-old infants. BGP was measured by radioimmunoassay. Each point represents the mean $\pm \mathrm{SE}$. Number of infants was; 3 of 0 day old, 6-13 of newborn, 27 of 1-month-old, 16 of 3month-old in the control group (--O---), 8-21 of newborn, 36 of 1-month-old, 18 of 3-month-old in the vitamin $\mathrm{K}$-administered group (- - ). *Significantly different from the control group each age at $p<0.01,{ }^{* *} p<0.05$. ${ }^{* * *}$ Significantly decreased from the level of 7th day in the control at $p<0.01$. 
day 3-5 and at 1 month. The difference in urinary Gla level between control and vitamin K-administered groups was the greatest at 1 month of age.

Normotest value linearly increased with age in both groups (Fig. 2). The value in the vitamin $\mathrm{K}$-administered group was significantly high compared with the control group at 1 month of age. In order to test the equality of the slope of the line between control and vitamin $\mathrm{K}$-administered groups by analysis of covariance, we estimated least squares regression line equations between Normotest values and age. The coefficient of the slope in the control group was 0.5934 , and in the vitamin $\mathrm{K}$ administered group, it was 0.6566 , and these values were not statistically different.

The effects of aging and vitamin $\mathrm{K}$ administration on the plasma BGP level are shown in Fig. 3. The plasma BGP level of control group increased linearly from $26.0 \mathrm{ng} / \mathrm{ml}$ on 0 day to $156.3 \mathrm{ng} / \mathrm{ml}$ on 7 th day, and then significantly decreased to $87.2 \mathrm{ng} / \mathrm{ml}$ at 1 month of age. The plasma BGP level in the vitamin $\mathrm{K}$-administered group was statistically lower than that in the control group from the 2 nd day to 1 month of age.

The effects of aging and vitamin $\mathrm{K}$ administration on relative amount of non$\gamma$-carboxylated BGP expressed as non- $\gamma$-carboxylated BGP level divided by total

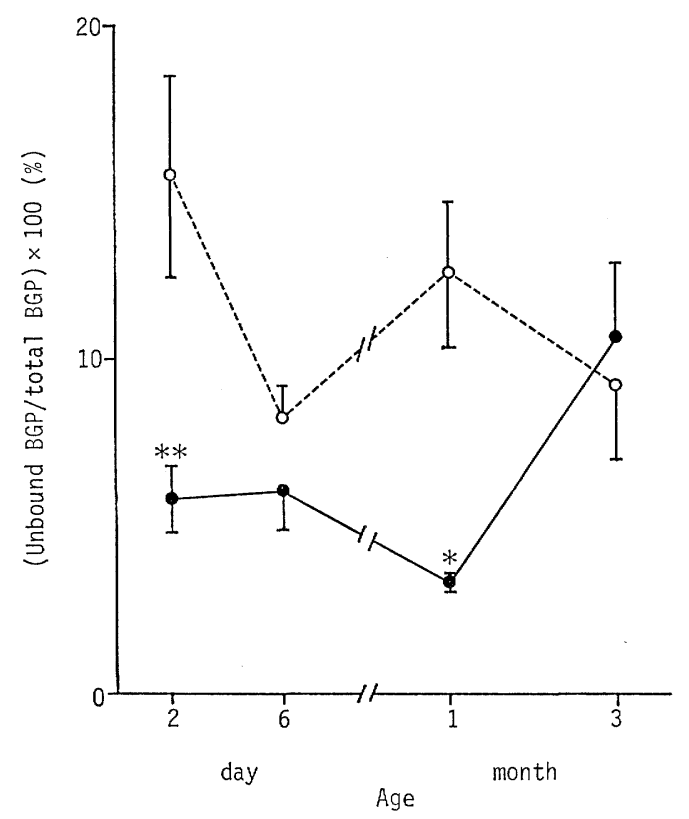

Fig. 4. Effects of aging and vitamin $\mathrm{K}$ administration on relative amount of non- $\gamma$-carboxylated BGP in plasma. Relative amount of non- $\gamma$-carboxylated BGP in plasma was expressed as the amount of BGP level which was not bound to hydroxyapatite divided by total BGP level in per cent (N/T ratio). Each point represents the mean $\pm \mathrm{SE}$ of 6 newborn infants and 7-9 of 1 or 3-month-old infants. -- - --, control group; - - - vitamin $\mathrm{K}$-administered group. *Significantly different from the control at $p<0.01, * * p<0.05$.

Vol. 2, No. 3, 1987 


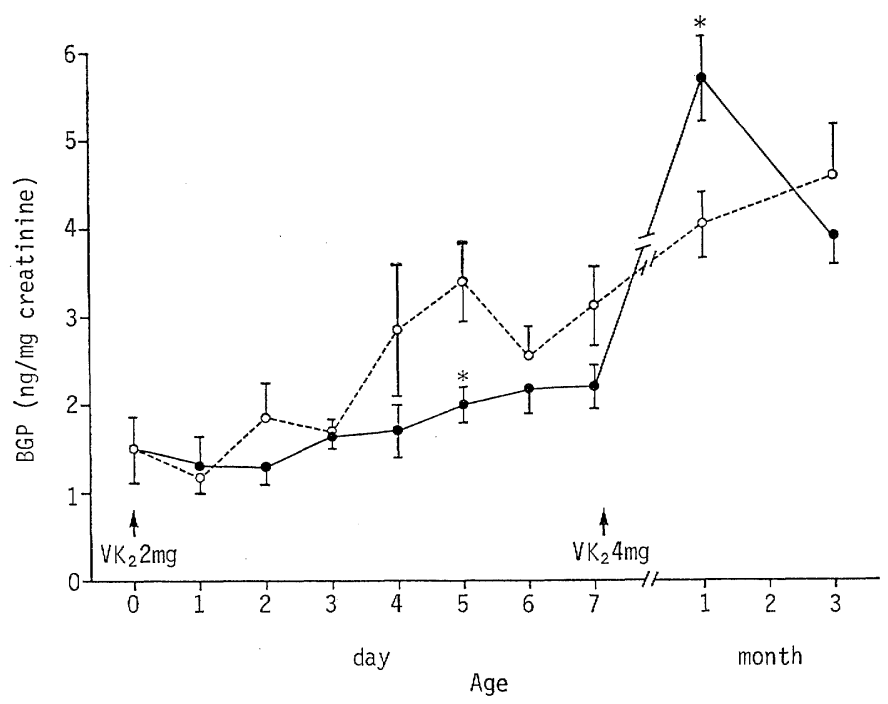

Fig. 5. Effects of aging and vitamin $\mathrm{K}$ administration on urinary BGP level in 0-3-monthold infants. Each point represents the mean \pm SE. Number of infants was; same as the newborn infants whose plasma BGP were measured in both groups, 18 of 1-month-old, 9 of 3-month-old in the control group (--O---), 37 of 1-month-old, 9 of 3-month-old in the vitamin $\mathrm{K}$ administered group (- - ). *Significantly different from corresponding age in the control group at $p<0.05$.

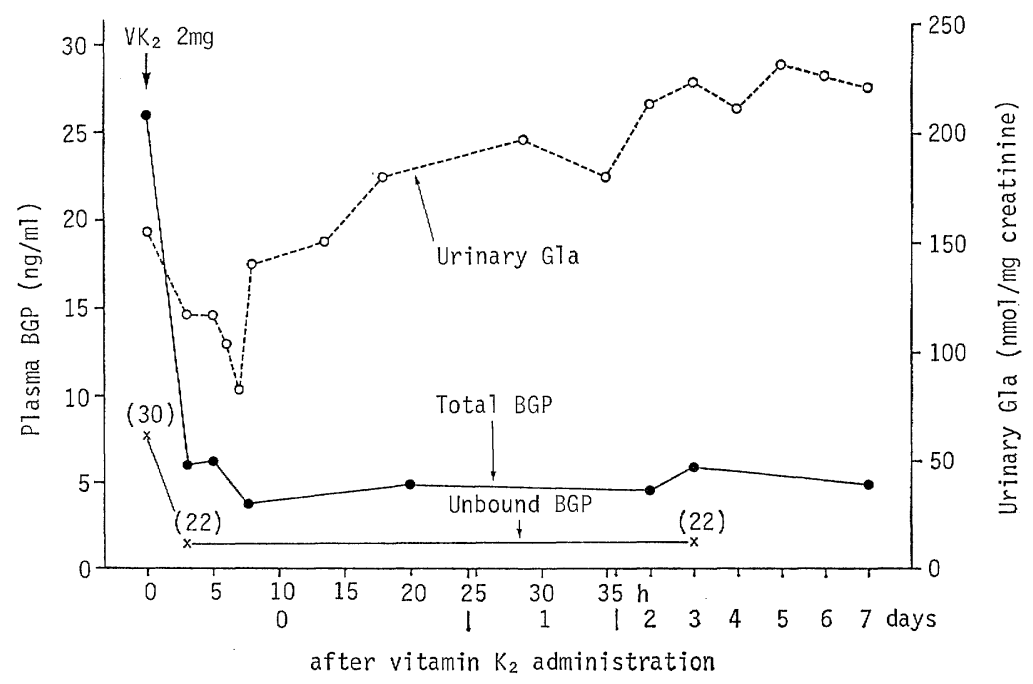

Fig. 6. Effect of vitamin K therapy on total BGP and BGP not bound to hydroxyapatite in serum and urinary Gla level in a vitamin $\mathrm{K}$ deficient patient. The number in parentheses, $\mathrm{N} / \mathrm{T}$ ratio $(\%)$. 
BGP level in per cent (N/T ratio) are shown in Fig. 4. The N/T ratio in the control group was about $16 \%$ on day 2 , decreased below $10 \%$ on day 6 , and then increased to $12 \%$ at 1 month of age. The $\mathrm{N} / \mathrm{T}$ ratio in the vitamin $\mathrm{K}$-administered group was significantly lower than that in the control group on the 2 nd day and at 1 month.

The urinary BGP level in the control group increased with age to 3 months. There was no change at 1 month even though the plasma BGP level showed a significant change at that time. The urinary BGP level in the vitamin K-administered group increased gradually as the same as that in the control group, but was lower than the control level in the early neonatal period. However, the situation at 1 month was reversed i.e., it was higher than that in the control group (Fig. 5).

The effects of vitamin $K$ therapy on plasma BGP and urinary Gla levels in a case of vitamin $K$ deficiency

The changes in plasma BGP and urinary Gla levels after intravenous administration of vitamin $\mathrm{K}$ to a patient with vitamin $\mathrm{K}$ deficiency associated with intracranial hemorrhage were observed (Fig. 6). This patient was a 33-day-old and breast-fed male infant. Prior to admission, no medication was given, not even vitamin $\mathrm{K}$, and there was no evidence of vitamin $\mathrm{K}$ deficiency after birth. Results of coagulation studies at admission were shown as follows: Normotest value, $<5 \%$; thrombotest, $<5 \%$; prothrombin time, $>123.3 \mathrm{~s}$ (control $=12-15 \mathrm{~s}$ ); active partial thromboplastin time, $>300 \mathrm{~s}$; fibrinogen, $220 \mathrm{mg} / \mathrm{ml}$; and PIVKA (Protein Induced by Vitamin $\mathrm{K}$ Absence or Antagonist)-II, 33.2 AU/ml (normal $<0.13 \mathrm{AU} /$ $\mathrm{ml}$ ). The last was measured by ELISA (Enzyme-Linked Immunosorbent Assay) using anti-PIVKA-II monoclonal antibody [25]. Four hours after vitamin K therapy, the Normotest value increased to $49 \%$, and then gradually increased to normal adult range. The urinary Gla level at admission, before vitamin $\mathrm{K}$ administration, was $155.5 \mathrm{nmol} / \mathrm{mg}$ creatinine, and this was on the lower border value of the control at 1 month. Seven and half hours after vitamin K therapy, urinary Gla level decreased to 85.3 , and thereafter increased to about 220 , this level corresponding to that of the vitamin $\mathrm{K}$-administered group at 1 month. The plasma BGP level at the admission was $26.0 \mathrm{ng} / \mathrm{ml}$, and the level rapidly decreased and maintained low level throughout after vitamin $\mathrm{K}$ administration. The $\mathrm{N} / \mathrm{T}$ ratio of plasma BGP at admission was $30 \%$ and after vitamin $\mathrm{K}$ therapy the amount of non- $\gamma$-carboxylated BGP rapidly decreased like the total plasma BGP level, however, the N/T ratio only slightly decreased, to $22 \%$.

\section{DISCUSSION}

In our study, the urinary Gla level in the control group was mostly steady except for a slight increase from the neonatal period to 1 month. On the other hand, the level in the vitamin $\mathrm{K}$-administered group increased with age to 1 month 
and was significantly higher than the control level. These findings suggest that there are non- $\gamma$-carboxylated and/or newly synthesized vitamin $\mathrm{K}$ dependent proteins which are converted to the $\gamma$-carboxylated form by vitamin $\mathrm{K}$ administration, resulting in the increase in urinary Gla. Since free Gla is not metabolized, but excreted quantitatively [26], the urinary level of free Gla can be used to measure the overall status of vitamin K-dependent processes. The fact that the difference in urinary Gla level between the two groups was maximum at 1 month suggests that the metabolism of vitamin K-dependent proteins is the greatest at that time.

The origin of Gla in the body is probably from the catabolism of Gla containing proteins. By calculation of prothrombin turnover in man, Levy and Lian reported that the urinary excretion of Gla correlates with the endogenous turnover of vitamin K-dependent coagulation factors [27]. The kinetics of Gla excretion by patients recently treated with warfarin demonstrates that the urinary Gla level correlates with prothrombin time, however, about $25 \%$ of the total normal urinary Gla level is unaffected [27]. They suggest that the Gla-containing proteins of extrahepatic origin probably contribute to urinary Gla at this level. In infants, the contribution rate of each Gla-containing protein to the urinary Gla level is not known yet. In our study, the Normotest value in the vitamin $\mathrm{K}$ administered group was higher than the control value at 1 month, however, the slopes for age versus Normotest value between both groups were not significantly different. Therefore the highest increment of urinary Gla excretion in vitamin $\mathrm{K}$-administered group at 1 month of age cannot be explained. Moreover, it is reported that the appearance of PIVKAII in blood is greatest at 2-3 days after birth and gradually decreases [28]. PIVKAII is an abnormal prothrombin which cannot bind to $\mathrm{Ca}^{2+}$ ions because of absence of Gla residues in the molecule. If Gla residues, originating from vitamin Kdependent coagulation factors, account for the increase in urinary Gla level at 1 month, the slopes for age of Normotest values between the two groups must be different significantly and PIVKA-II should be maximally present at 1 month. As this was not the case, we speculated that coagulation factors contribute little to increased urinary Gla excretion following vitamin K-administration, especially at 1 month of age.

BGP may contribute more to the urinary Gla level in infants whose bone development is the greatest after birth than in adults, because BGP is thought to be a protein which regulates bone mineralization [15, 29-31]. The plasma BGP level in the control group of our study was quite higher than those of children and adults in previous reports [32-34]. One possible explanation for the high BGP level in plasma is that it reflects increased bone resorption and increased bone formation. Cases of metabolic bone diseases which induce an increase in bone turnover, such as Paget's disease, metastatic bone cancer, primary hyperparathyroidism, and osteogenesis imperfecta, show a high plasma BGP level [33-37]. Another possibility is that there exists non- $\gamma$-carboxylated BGP which cannot bind to bone hydroxyapatite. Native BGP, which contains Gla residues, binds to hydroxyapatite more strongly than BGP in which all three Gla residues have been thermally decar- 
boxylated to glutamic acid [29]. Because vitamin K-dependent region where Gla residues exist is not a part of the antigenic determinant, the radioimmunoassay detects non- $\gamma$-carboxylated BGP as well as the $\gamma$-carboxylated form [22]. In order to distinguish these two forms of BGP in plasma, it is useful to take advantage of their different binding to hydroxyapatite. Price et al. demonstrated that warfarin administration to a 1-month-old rat produces a rapid, 3-fold increase in serum BGP which does not bind to hydroxyapatite and so is non- $\gamma$-carboxylated, and they showed that BGP content in the bone decreases [24, 38]. The hydroxyapatite binding assay in our study showed that there exists non- $\gamma$-carboxylated BGP in early infants, and this is probably due to latent vitamin $\mathrm{K}$ deficiency which is denoted by the presence of PIVKA-II and increased urinary Gla following vitamin $\mathrm{K}$ administration. However, the level of non- $\gamma$-carboxylated BGP was lower than the level we expected. Poser et al. demonstrated that native and decarboxylated BGP binds with nearly equal affinity to hydroxyapatite, showing that Gla residues in the bone are not required for binding to hydroxyapatite crystals [29]. They speculated that the native Gla protein interacts differently with the initially formed $\mathrm{Ca}^{2+}$ and $\mathrm{HPO}_{4}{ }^{2-}$ aggregate than it does with the final hydroxyapatite crystals, because the Gla residues are required for the protein to inhibit hydroxyapatite crystallization by tight binding to the hydroxyapatite surface. The lower plasma BGP level than we expected may be due to the difference in the surface character between the hydroxyapatite which was used in our study and the final hydroxyapatite crystals in vivo. However, the level of non- $\gamma$-carboxylated BGP in our study may reflect a part of the state of $\gamma$-carboxylation of BGP in plasma. Therefore, the high plasma BGP level during this period is due to both increased bone metabolism and the release of the fraction of new BGP which would be deposited in bone.

The total plasma BGP level at 1 month in the control group was still higher than that in the vitamin $\mathrm{K}$-administered group despite its significant decrease from the peak level on the 7 th day, and the N/T ratio returned to higher level. Though the reason of this change in plasma BGP is not clearly understood, we speculated that plasma BGP which has Gla residues would shift from blood to bone, because the urinary BGP level in the control group almost linearly increased with age and did not show any changes which could explain the change in the plasma BGP level at 1 month. If this speculation is correct, bone requires more BGP at 1 month than in the neonatal period. Simultaneously, BGP synthesis may increase, since the percentage of non- $\gamma$-carboxylated BGP increased.

In our patient having coagulopathy with vitamin $\mathrm{K}$ deficiency, the plasma BGP level was lower than the level in the control group at 1 month, and the N/T ratio was higher than that of the control though the non- $\gamma$-carboxylated BGP level was almost the same as that of the control. Because BGP synthesis is inhibited by warfarin administration [39], vitamin $\mathrm{K}$ is thought to have a role in the synthesis of BGP as well as in $\gamma$-carboxylation. At one month of age, the deposition of BGP is thought to be accelerated and BGP is newly synthesized and $\gamma$-carboxylated in 
the presence of vitamin $\mathrm{K}$. However, on the occasion of vitamin $\mathrm{K}$ deficiency, there may be no newly synthesized BGP and consequently plasma BGP level may decrease and the $\mathrm{N} / \mathrm{T}$ ratio increase.

The plasma BGP level in the vitamin K-administered group was lower than that in the control group and increased almost linearly to 3 month of age, and $\mathrm{N} / \mathrm{T}$ ratio was also lower in the former group. It is reported that after the administration of vitamin $\mathrm{K}$ to rats treated with warfarin on a long term basis, there is a rapid disappearance from plasma of BGP species which would bind to hydroxyapatite followed by accumulation of BGP in the bone [24]. Our results suggest that non- $\gamma$-carboxylated BGP in plasma is changed to the $\gamma$-carboxylated form and deposited in bone, and then is degraded to Gla and excreted in urine following vitamin $\mathrm{K}$ administration in the neonatal period. At one month of age, though the plasma BGP level was still lower in vitamin $\mathrm{K}$-administered group than in the control, the urinary BGP level was higher in the treated group, unlike in the neonatal period. Since almost all of the BGP in plasma in the vitamin K administered group may be $\gamma$-carboxylated through vitamin $\mathrm{K}$ and deposited to bone throughout the neonatal period, excessive BGP which is formed as in the result of increased bone turnover and BGP synthesis at 1 month may be excreted in the urine. Gla residues originating from BGP are also excreted, resulting in high urinary level of Gla. On the other hand, in the control group there may not be enough deposition of $\gamma$-carboxylated BGP during the neonatal period because of latent vitamin $\mathrm{K}$ deficiency, so it is difficult to see the increased urinary BGP and Gla excretion at 1 month of age despite the increased BGP turnover, unlike in the vitamin K-administered group.

All of the results in our series of experiments suggest that BGP turnover and accelerates especially at 1 month of age. The reason for this physiological change is unknown, however, BGP function may provide us with a possible explanation. It is reported that the appearance of Gla during differentiation and development of endochondral bone can be correlated with the onset of mineralization [40]. Price et al. reported that the level of BGP in rat bone rises rapidly after birth and that this increase parallels the transition from the amorphous calcium phosphate phase of fetal bone to the hydroxyapatite mineral of adult bone [30]. And BGP appears in human bone mineral shortly after the quantity of mineral phosphate has attained levels sufficient to be detected [31]. Because BGP inhibits hydroxyapatite crystallization [15, 29], and may appear concurrently with the mineral transition and with appearance of hydroxyapatite, they speculated that its function could be to catalyze the transition to hydroxyapatite, to regulate the size or shape of the hydroxyapatite crystals formed, or to orient the crystals epitactically along the collagen fiber. Moreover, it is reported that when a rat is warfarin-treated for 8 months closure of the epiphysis and the bony union of epiphysis and metaphysis in the tibia, along with associated cessation of all longitudinal growth, occur [41]. These bony changes closely resemble warfarin-induced embryopathy which shows stippling in uncalcified epiphyseal regions and in certain cartilages and soft tissues 
secondary to abnormal calcification [42]. Therefore, BGP may also play a role in the regulation of mineralization by inhibition of excessive hydroxyapatite crystallization.

In human development, the bone formation and the rate of bony elongation are greatest during the early infantile period. To achieve normal bone development, mineralization should be well regulated and not manifest any abnormal changes, such as excessive mineralization which may interfere with bony elongation. One possible function of BGP may be regulation of mineralization; therefore, the deposition of BGP in bone as well as synthesis and $\gamma$-carboxylation of BGP may act in the regulation of this great bone formation in early infancy, especially at 1 month of age. Consequently the requirement for vitamin $\mathrm{K}$ may also increase at that time. Furthermore, if there are risk factors which cause decreased intake of vitamin $\mathrm{K}$, the infant will fall into an apparently vitamin $\mathrm{K}$ deficient state. Therefore, we suspect that the increased BGP turnover to regulate bone development occurs physiologically at 1 month of age and that this plays a major role in the induction of vitamin $\mathrm{K}$ deficiency at that time.

This study was supported, in part, by the grants from the Morinaga Hōshi-kai and the Ministry of Health and Welfare, Japan.

The authors thank Mr. Hisayoshi Kondo for assistance in carrying out statistical analyses, and Dr. Kunihiko Motohara for his help in measuring PIVKA-II.

\section{REFERENCES}

1. Goldman, H.I., and Deposito, F. (1966): Hypoprothrombinemic bleeding in young infant. Am. J. Dis. Child., 111, 430-432.

2. Taj-Eldin, S., Al-Nouri, L., and Fakri, O. (1967): Haemorrhagic diathesis in children associated with vitamin K deficiency. J. Clin. Path., 20, 252-256.

3. Nammacher, M.A., Willemin, M., Hartmann, J.R., and Gaston, L.W. (1970): Vitamin K deficiency in infants beyond the neonatal period. J. Pediatr., 76, 549-554.

4. Visudhiphan, P., Bhachet, P., Lakanapichanchat, C., and Chiemchanya, S. (1974): Intracranial hemorrhage in infants due to acquired prothrombin complex deficiency. J. Neurosurg., 41, 14-19.

5. Israngkura, P.B., and Kashemsant, C. (1975): A bleeding syndrome in infants: Acquired prothrombin complex deficiency of unknown aetiology. Southeast Asian J. Trop. Med. Pub. Hlth., 6, 592-598.

6. Matsusaka, T., Katayama, K., Tsuji, Y., Yasunaga, A., and Mori, K. (1981): Intracranial hemorrhage due to vitamin $\mathrm{K}$ deficiency in infants: its importance as a cause of intracranial hemorrhage in infants. No To Shinkei, 33, 989-997.

7. O'Connor, M.E., Livingstone, D.S., Hannah, J., and Wilkins, D. (1983): Vitamin K deficiency and breast-feeding. Am. J. Dis. Child., 137, 601-602.

8. Lane, P.A., Hathaway, W.E., Githens, J.H., Krugman, R.D., and Rosenberg, D.A. (1983): Fatal intracranial hemorrhage in a normal infant secondary to vitamin $\mathrm{K}$ deficiency. Pediatrics, 72, 562-564.

9. Chaou, W.-T., Chou, M.-L., and Eitzman, D.V. (1984): Intracranial hemorrhage and vitamin $\mathrm{K}$ deficiency in early infancy. $J$. Pediatr., 105, 880-884.

10. Motohara, K., Matsukura, M., Matsuda, I., Iribe, K., Ikeda, T., Kondo, Y., Yonekubo, A.,

Vol. 2, No. 3, 1987 
Yamamoto, Y., and Tsuchiya, F. (1984): Severe vitamin K deficiency in breast-fed infants. J. Pediatr., 105, 943-945.

11. Shirahata, A., Nojiri, T., Miyaji, Y., Yamada, K., Ikeda, I., Takii, Y., Suzuki, H., and Sato, S. (1981): Vitamin K contents of infant formula products and breast milk. Igakunoayumi, 118, 857-859 (in Japanese).

12. Isarangkura, P.B., Mahadandana, C., Panstienkel, B., Nakayama, K., Tsukimoto, I., Yamamoto, Y., and Yonekubo, A. (1983): Vitamin K level in maternal breast milk of infants with acquired prothrombin complex deficiency syndrome. Southeast Asian J. Trop. Med. Public Health, 14, 275-276.

13. Bentley, R., and Meganathan, R. (1982): Biosynthesis of vitamin K (menaquinone) in bacteria. Microbiol. Rev., 46, 241-280.

14. Hauschka, P.V., Lian, J.B., and Gallop, P.M. (1975): Direct identification of the calciumbinding amino acid, $\gamma$-carboxyglutamate, in mineralized tissue. Proc. Natl. Acad. Sci. USA, 72, 3925-3929.

15. Price, P.A., Otsuka, A.S., Poser, J.W., Kristaponis, J., and Raman, N. (1976): Characterization of a $\gamma$-carboxyglutamic acid-containing protein from bone. Proc. Natl. Acad. Sci. USA, 73, 1447-1451.

16. Poser, J.W., Esch, F.S., Ling, N.C., and Price, P.A. (1980): Isolation and sequence of the vitamin $\mathrm{K}$-dependent protein from human bone: Undercarboxylation of the first glutamic acid residue. J. Biol. Chem., 255, 8685-8691.

17. Stenflo, J., Fernlund, P., Egan, W., and Roepstorff, P. (1974): Vitamin K dependent modifications of glutamic acid residues in prothrombin. Proc. Natl. Acad. Sci. USA, 71, 27302733.

18. Hauschka, P.V., Lian, J.B., and Gallop, P.M. (1978): Vitamin K and mineralization. Trends Biochem. Sci., 3, 75-78.

19. Kuwada, M., and Katayama, K. (1981): A high-performance liquid chromatographic method for the simultaneous determination of $\gamma$-carboxyglutamic acid and glutamic acid in proteins, bone, and urine. Anal. Biochem., 117, 259-265.

20. Benson, J.R., and Hare, P.E. (1975): $o$-Phthalaldehyde: fluorogenic detection of primary amines in the picomole range. Comparison with fluorescamine and ninhydrin. Proc. Natl. Acad. Sci. USA, 72, 619-622.

21. Owren, P.A., and Standli, O.K. (1969): Normotest. Farmakoterapi, 25, 14-26.

22. Price, P.A., and Nishimoto, S.K. (1980): Radioimmunoassay for the vitamin K-dependent protein of bone and its discovery in plasma. Proc. Natl. Acad. Sci. USA, 77, 2234-2238.

23. Otawara, Y., Hosoya, N., Moriuchi, S., Kasai, H., and Okuyama, T. (1980): Purification and characterization of calcium-binding protein containing $\gamma$-carboxyglutamic acid from rat bone. J. Nutr. Sci. Vitaminol., 26, 209-219.

24. Price, P.A., Williamson, M.K., and Lothringer, J.W. (1981): Origin of the vitamin Kdependent bone protein found in plasma and its clearance by kidney and bone. J. Biol. Chem., 256, 12760-12766.

25. Motohara, K., Kuroki, Y., Kan, H., Endo, F., and Matsuda, I. (1985): Detection of vitamin $\mathrm{K}$ deficiency by use of an enzyme-linked immunosorbent assay for circulating abnormal prothrombin. Pediatr. Res., 19, 354-357.

26. Shah, D.V., Tews, J.K., Harper, A.E., and Suttie, J.W. (1978): Metabolism and transport of $\gamma$-carboxyglutamic acid. Biochim. Biophys. Acta, 539, 209-217.

27. Levy, R.J., and Lian, J.B. (1979): $\gamma$-Carboxyglutamate excretion and warfarin therapy. Clin. Pharmacol. Ther., 25, 562-570.

28. Motohara, K., Endo, F., and Matsuda, I. (1985): Effect of vitamin K administration on acarboxy prothrombin (PIVKA-II) levels in newborns. Lancet, 2, 242-244.

29. Poser, J.W., and Price, P.A. (1979): A method for decarboxylation of $\gamma$-carboxyglutamic 
acid in proteins: properties of the decarboxylated $\gamma$-carboxyglutamic acid protein from calf bone. J. Biol. Chem., 254, 431-436.

30. Price, P.A., Lothringer, J.W., and Nishimoto, S.K. (1980): Absence of the vitamin Kdependent bone protein in fetal rat mineral: evidence for another $\gamma$-carboxyglutamic acidcontaining component in bone. J. Biol. Chem., 255, 2938-2942.

31. Price, P.A., Lothringer, J.W., Baukol, S.A., and Reddi, A.H. (1981): Developmental appearance of the vitamin K-dependent protein of bone during calcification: analysis of mineralizing tissues in human, calf, and rat. J. Biol. Chem., 256, 3781-3784.

32. Gundberg, C.M., Lian, J.B., and Gallop, P.M. (1983): Measurements of $\gamma$-carboxyglutamate and circulating osteocalcin in normal children and adults. Clin. Chim. Acta, 128, 1-8.

33. Cole, D.E.C., Carpenter, T.O., and Gundberg, C.M. (1985): Serum osteocalcin concentrations in children with metabolic bone disease. J. Pediatr., 106, 770-776.

34. Price, P.A., Parthemore, J.G., and Deftos, L.J. (1980): New biochemical marker for bone metabolism: measurement by radioimmunoassay of bone Gla protein in the plasma of normal subjects and patients with bone disease. J. Clin. Invest., 66, 878-883.

35. Deftos, L.J., Parthemore, J.G., and Price, P.A. (1982): Changes in plasma bone Gla protein during treatment of bone disease. Calcif. Tissue Int., 34, 121-124.

36. Gundberg, C.M., Lian, J.B., Gallop, P.M., and Steinberg, J.J. (1983): Urinary $\gamma$-carboxyglutamic acid and serum osteocalcin as bone markers: studies in osteoporosis and Paget's disease. J. Clin. Endocrinol. Metab., 57, 1221-1225.

37. Castells, S., Yasumura, S., Fusi, M.A., Colbert, C., Bachtell, R.S., and Smith, S. (1986): Plasma osteocalcin levels in patients with osteogenesis imperfecta. J. Pediatr., 109, 88-91.

38. Price, P.A., and Williamson, M.K. (1981): Effects of warfarin on bone: studies on the vitamin K-dependent protein of rat bone. J. Biol. Chem., 256, 12754-12759.

39. Price, P.A., Epstein, D.J., Lothringer, J.W., Nishimoto, S.K., Poser, J.W., and Williamson, M.K. (1979): Structure and function of the vitamin K-dependent protein of bone, in Vitamin K Metabolism and Vitamin K-Dependent Proteins, ed. by Suttie, J.W., University Park Press, Baltimore, pp. 219-226.

40. Hauschka, P.V., and Reddi, A.H. (1980): Correlation of the appearance of $\gamma$-carboxyglutamic acid with the onset of mineralization in developing endochondral bone. Biochem. Biophys. Res. Commun., 92, 1037-1041.

41. Price, P.A., Williamson, M.K., Haba, T., Dell, R.B., and Jee, W.S.S. (1982): Excessive mineralization with growth plate closure in rats on chronic warfarin treatment. Proc. Natl. Acad. Sci. USA, 79, 7734-7738.

42. Hall, J.G., Pauli, R.M., and Wilson, K.M. (1980): Maternal and fetal sequelae of anticoagulation during pregnancy. Am. J. Med., 68, 122-140. 